\title{
A Safe Evacuation Mode for Ultradeep Underground Space in Urban Rail Transit Stations
}

\author{
Lili Dong ${ }^{1}$, Jin $\mathrm{Wu}^{1}$, Wei Wang ${ }^{2 *}$ \\ ${ }^{1}$ School of Architecture and Urban Planning, Chongqing Jiaotong University, Chongqing 400074, China \\ ${ }^{2}$ School of Art, Design and Architecture, University of Huddersfield, Queensgate, Huddersfield, HD1 3DH, West Yorkshire, \\ United Kingdom
}

Corresponding Author Email: wei.wang2@hud.ac.uk

https://doi.org/10.18280/jesa.520407

Received: 19 March 2019

Accepted: 2 July 2019

\section{Keywords:}

safe evacuation mode, ultradeep underground public spaces, horizontal shelter, vertical evacuation system

\begin{abstract}
Recent years has seen the rapid development of rail transit and comprehensive development of underground and aboveground facilities. Against this backdrop, it is imperative to develop a suitable safe evacuation mode for ultradeep underground public spaces. From the perspective of building design, this paper combines the horizontal shelter and vertical evacuation system into a novel safe evacuation mode, consisting of horizontal evacuation, vertical escape route, emergency shelter, horizontal escape route, vertical evacuation system and exit evacuation. Then, building information modelling (BIM) was adopted to simulate the application of our safe evacuation mode to Hongtudi Station, Line 10 of Chongqing Rail Transit (CRT). The results prove that our safe evacuation mode is feasible for evacuating personnel in ultradeep underground public spaces. The research findings shed new light on the safe evacuation technology in ultradeep underground public spaces.
\end{abstract}

\section{INTRODUCTION}

In recent years, China has laid down many incentive policies on developing and utilizing underground spaces. In May 2016, the Chinese Ministry of Housing and Urban-Rural Development (MOHURD) issued the 13th Five-Year Plan for the Development and Utilization of Urban Underground Spaces. The Plan specifies that urban underground spaces must be developed and utilized in an overall, systematic manner, and sets out the following principles: combine peacetime and wartime purposes, coordinate underground and aboveground functions, construct multiple layers in the vertical direction, and connect related spaces in the horizontal direction. Similarly, the Comprehensive National Disaster Prevention and Alleviation Plan (2016-2020), released by the General Office of the State Council, calls for further improvement to the mechanism for disaster prevention, alleviation and relief, and the perfection of relevant laws and regulations in 2016 2020. Against this backdrop, the underground public spaces should be developed and utilized, with emphasis on the prevention and control of fire accidents, as well as the safe and rapid evacuation of personnel in disasters.

The research on safe evacuation of personnel can be traced back to the late 1970s. For instance, Castle and Longley [1] established a security risk management system based on GIS. Alexander and Cruz [2] explored the automatic fire control system for underground spaces. Using a 3D numerical model, Yoneyama et al. [3] numerically analyzed the water depth and feasibility of safe evacuation in urban underground spaces under sudden floods. Li [4] examined and summed up the fire compartments in underground spaces, and pointed out the keys to the design of fire compartments and safe evacuation in civil underground space. In cooperation with Wuhan University, the City University of Hong Kong has established a process simulation model SEGM based on local fine mesh and individual description for underground space fire protection technology research and product development [5]. Overall, the existing studies on the safe evacuation in underground spaces mainly focus on equipment performance, management system and personnel behavior. There is no report on the evacuation mode for underground spaces.

To make up for the gap, this paper attempts to develop a complete and comprehensive mode for safe evacuation in underground spaces, and verify the mode performance in actual underground spaces.

\section{PROBLEMS WITH URBAN UNDERGROUND PUBLIC SPACES}

\subsection{Limitation on horizontal depth}

From 2011 to 2015, the urban underground spaces in China increased annually by more than $20 \%$. The ratio of underground spaces to surface buildings that are completed in the same period grew from $10 \%$ to $15 \%$. Several trends have emerged in the development and utilization of urban underground spaces: from civil defense to transport and other functions, from shallow layer to deep layer, and from small single-purpose structure to multi-purpose complex structure. However, ultradeep underground public spaces $(>10 \mathrm{~m}$ in depth) have not been well developed or utilized, because the current Code for Fire Protection Design of Buildings (GB50016-2014) only stipulated on the safe evacuation in underground public spaces within the buried depth of $10 \mathrm{~m}$. There are only a few cases of successful development and utilization of ultradeep underground public spaces in China. The deepest underground space for building is the $36 \mathrm{~m}$-deep basement of Star Harbor International Center in North Bund, 
Shanghai, while the deepest underground space for transport is the 94m-deep hall of Hongtudi Station, Line 10 of Chongqing Rail Transit (CRT).

\subsection{Limitation on fire evacuation facilities}

Underground spaces are concealed and closed. Any disaster in such spaces may lead to heavy casualties. About $36.11 \%$ of all accidents in underground spaces are fire, more frequent than any other disaster [6]. Moreover, fire is often accompanied by secondary disasters like gas explosion and poisoning. Statistics (Figure 1) show that $57 \%$ of metro accidents are caused directly or indirectly by fire [7].

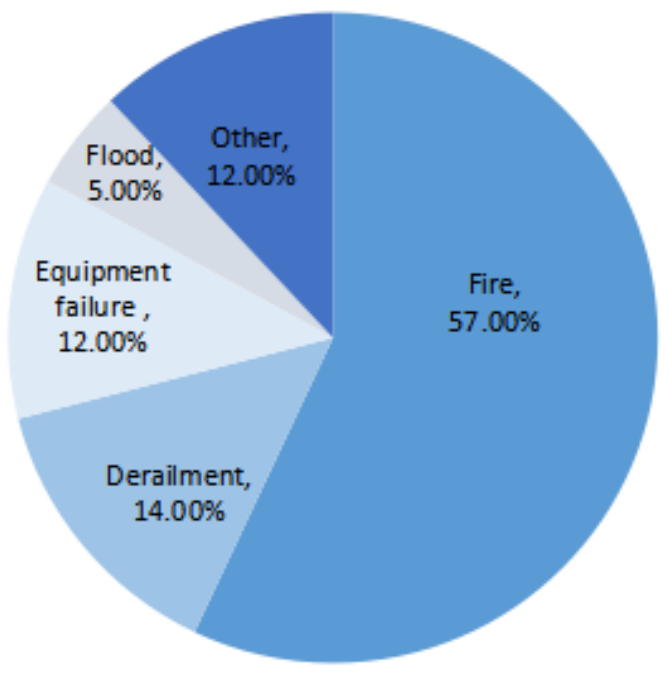

Figure 1. Statistics on metro accidents

Compared with surface buildings, underground buildings have a few exits and routes for fire evacuation. In the event of fire, the personnel need to escape upwards, adding to the evacuation difficulty [8]. The fire hazard is further magnified by the fact that the smoke spreads in the same direction with the evacuees. In GB50016-2014, it is clear that elevators are not safe for evacuation. However, it is both time-consuming and physically challenging to climb up the stairs. Therefore, the limitation on fire evacuation facilities is another bottleneck to the development and utilization of ultradeep underground spaces.

\section{SAFE EVACUATION MODE FOR ULTRADEEP UNDERGROUND PUBLIC SPACES}

Like that of surface buildings, the current evacuation mode for underground public spaces covers three parts: Horizontal evacuation, vertical upward evacuation and exit evacuation. Considering the peculiarity and complexity of ultradeep underground public spaces, this paper attempts to create a comprehensive safe evacuation mode coupling horizontal shelter and vertical evacuation system, in the light of building design and relevant laws and regulations.

\subsection{Horizontal shelter}

For some large or deep underground spaces, safe evacuation does not necessarily means evacuating personnel to the ground. The evacuees can also be guided to a safe place called the shelter [9], and wait to be transferred and rescued. The shelter is designed to solve the defects of underground buildings in fire: it is impossible to evacuate all personnel to the ground at once from ultradeep underground public spaces, due to the few exits and long escape route [10].

The shelters can be arranged in three patterns: decentralized, centralized and parallel. (1) In the decentralized pattern, the crowd is dispersed to shelters in the surroundings, reducing the crowdedness of each shelter. However, some may get lost as the evacuation direction is unclear. (2) In the centralized pattern, people from all directions are assembled in a large shelter at the center of the main space underground. In this case, the evacuation direction is clear, but the shelter is crowded. Besides, this pattern also constrains the design of the main space. (3) In the parallel pattern, the shelters are arranged in the upper or lower part of the main space underground to shorten the horizontal evacuation distance (Figure 2). Taking the Qianjiang Tunnel in Hangzhou for example, the shelters are placed below the main road, and linked up by stairs or slides, which are deployed at regular intervals along the tunnel (Figure 3). Under emergencies, the personnel can enter the nearest shelter, and travel along the shelters to the ends of the tunnel.

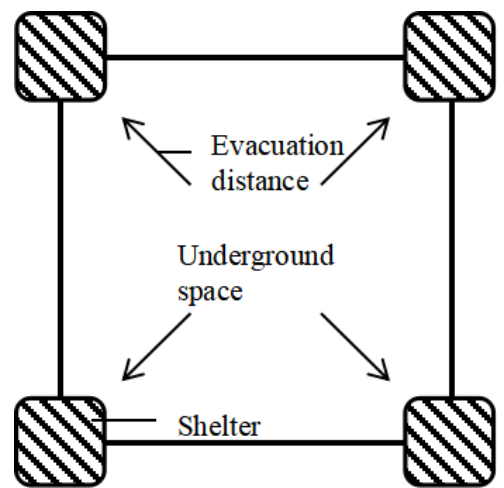

(a) Decentralized pattern

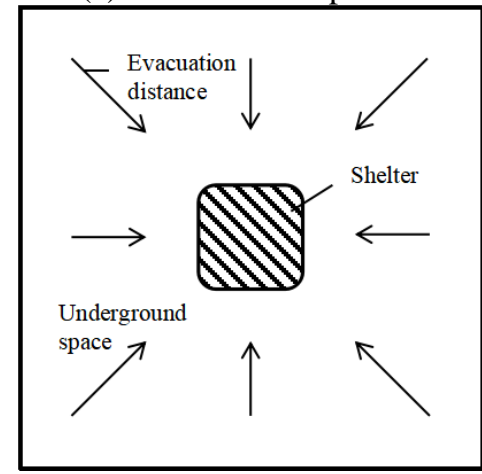

(b) Centralized pattern

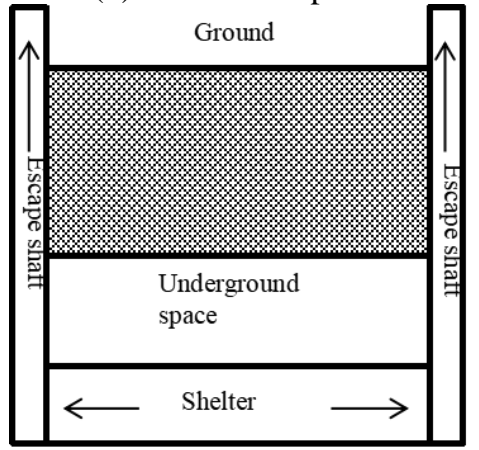

(c) Parallel pattern

Figure 2. Three patterns of shelters 


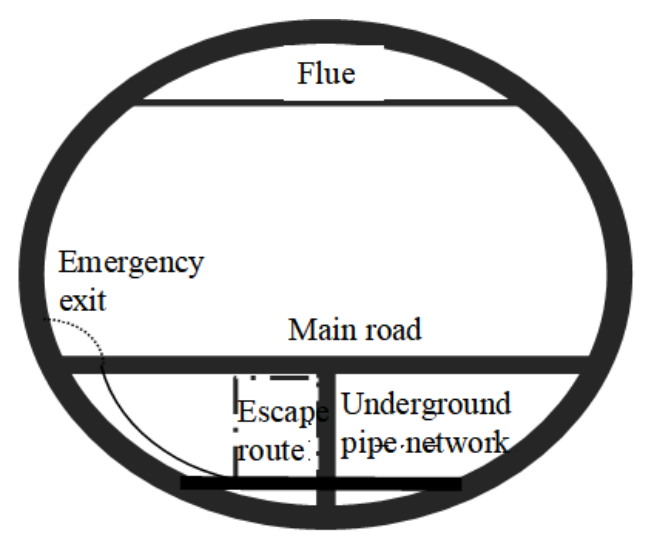

Figure 3. Profile of the evacuation mode in Qianjiang Tunnel

In real-world scenarios, an ultradeep underground public space is usually divided into multiple small spaces with varied functions. Putting the economic factor aside, the parallel pattern should be prioritized for shelter design in such a space,

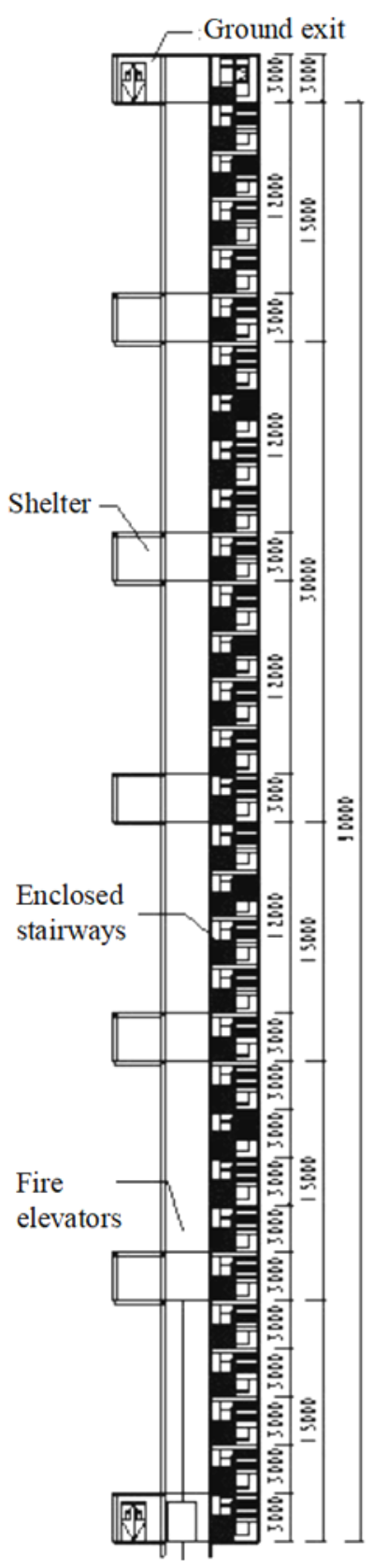

which could reduce the horizontal evacuation distance and shorten the egress time. In addition, the shelters should be placed in the lower part of the main space, for the smoke spreads along the evacuation direction in fire.

\subsection{Vertical evacuation system}

As mentioned before, it is both time-consuming and physically challenging to evacuate by stairs. To solve the problems, the author drew on the principle of escape shaft, and created a vertical evacuation system combining fire elevators and enclosed stairways (Figure 4). In the system, the stairways and elevators work together to transport evacuees upward, such that they could reach the ground directly via the evacuation exits. The parameters of the stairways and elevators were selected as per the requirements on fire evacuation. The number of stairways and elevators were determined according to the depth of the ultradeep underground public space and the total number of evacuees.
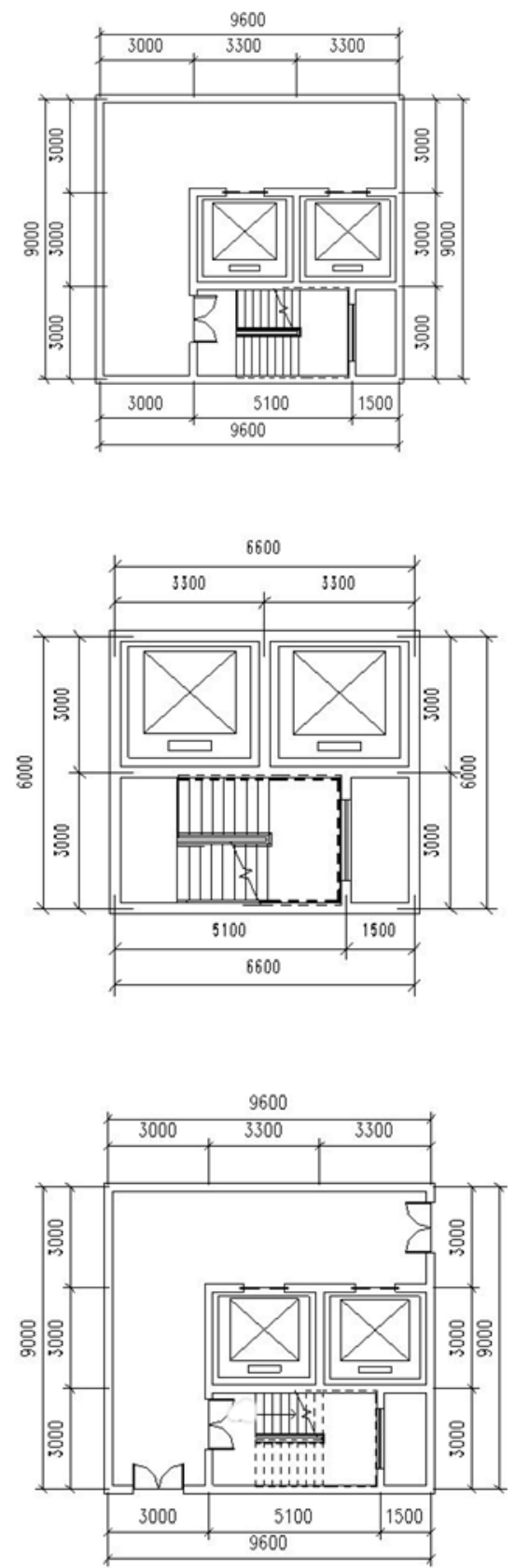

Figure 4. Profile of vertical evacuation system 


\subsection{Safe evacuation mode}

This paper designs a complete safe evacuation mode in the following steps. First, stairs and slides were arranged at regular intervals in the ultradeep underground public space, forming vertical escape routes that link up the shelters below the public space. Next, an isolation space was designed between each shelter and escape route for pressurized air supply, which prevents the spread of smoke in the shelter (Figure 5). In addition, the vertical evacuation system was separated from the underground public space, such that the system will not be affected by fire or explosion in the space. Finally, the horizontal shelters were connected to the vertical evacuation system via horizontal escape routes, forming the entire safe evacuation mode (Figure 6). Safe evacuation mode involving horizontal evacuation, vertical downward evacuation, temporary shelter, horizontal evacuation, vertical evacuation and exit evacuation.

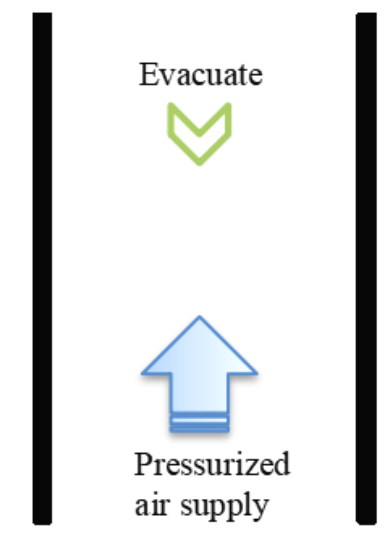

Figure 5. The isolation space

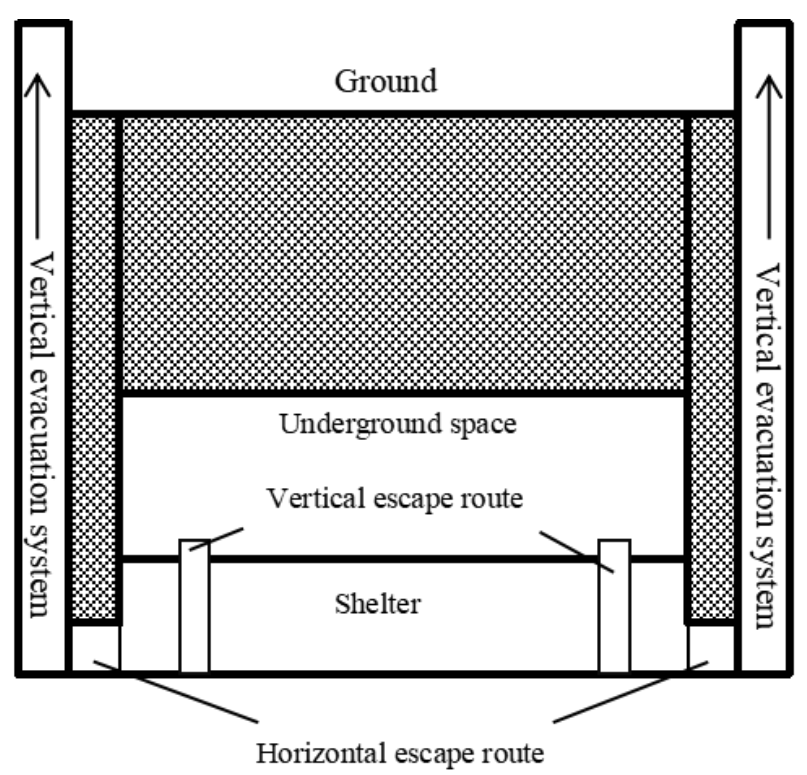

Figure 6. The safe evacuation system

To sum up, our safe evacuation mode provides a new evacuation path: from horizontal evacuation, vertical escape route, shelter, horizontal escape route, vertical evacuation system, to evacuation exit. Compared with conventional safe evacuation mode, our mode features high safety and short egress time, and thus reduces the fire casualties.

\section{FEASIBILITY OF SAFE EVACUATION MODE}

\subsection{Features of safe evacuation mode}

(1) The horizontal evacuation distance is shortened. The horizonal shelters effectively shorten the distance of horizontal evacuation, reduce the stay in the fireground, and thus lower the casualties. In addition to physical protection, the shelters can comfort the evacuees mentally. The safe evacuation mode enables the personnel to evacuate by themselves, rather than wait passively for rescue.

(2) The smoke spreads opposite to the evacuation direction. In our safe evacuation mode, the shelters below the underground space are linked up by slides. In this way, the personnel evacuate in the opposite direction of the spreading smoke. During the evacuation, the personnel will inhale fewer hazardous gas, feel less panic in the unfamiliar environment, and make more rational judgement of the escape route.

(3) The evacuation is efficient in the vertical direction. As shown in Table 1, the mean upward speed on stairs is $0.5 \mathrm{~m} / \mathrm{s}$, much slower than the mean speed of elevator $(2.5 \mathrm{~m} / \mathrm{s})$ [11]. In our safe evacuation mode, fire elevators are included in the vertical evacuation system, according to relevant standards. With the aid of these fire elevators, the personnel can be evacuated much more rapidly in the vertical direction from ultradeep underground public spaces [12].

Table 1. Movement speeds of personnel. Source: Modern Building Fire Protection Design Technology

\begin{tabular}{cccc}
\hline \multicolumn{2}{c}{ Mean walking speed $(\mathbf{m} / \mathbf{s})$} & \multicolumn{2}{c}{ Mobility coefficient (person/m·s) } \\
\hline $\begin{array}{c}\text { Horizontal } \\
\text { speed }\end{array}$ & $\begin{array}{c}\text { Upward } \\
\text { speed on } \\
\text { stairs }\end{array}$ & $\begin{array}{c}\text { Horizontal } \\
\text { speed }\end{array}$ & $\begin{array}{c}\text { Upward speed on } \\
\text { stairs }\end{array}$ \\
1.2 & 0.6 & 1.6 & \\
1.0 & 0.5 & 1.5 & 1.4 \\
0.8 & 0.4 & 1.3 & 1.3 \\
\hline
\end{tabular}

\subsection{Safe egress time}

The ultimate goal of safe evacuation design is to make the required safe egress time (RSET) smaller than the available safe regress time (ASET) (Figure 7), that is $T_{\mathrm{RSET}}<T_{\mathrm{ASRT}}[13$, 14]. The RSET refers to the time needed for the personnel to complete safe evacuation, and the ASRT means the time from the start of smoke diffusion to the onset of the hazardous situation, i.e. the time that the personnel are threatened by hazardous smoke.

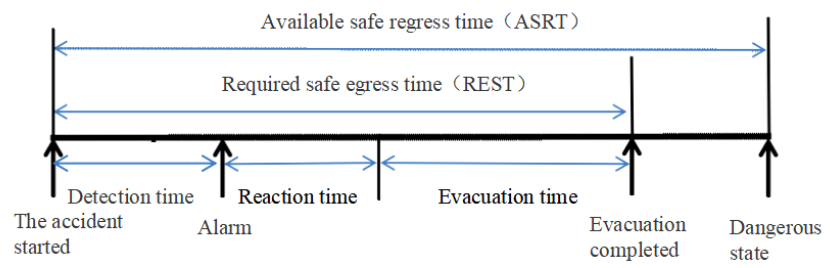

Figure 7. Relationship between phases of fire development and safe egress time

\subsubsection{Determination of the ASRT}

In the event of fire, the ASRT mainly depends on the disaster evolution. The ASRT value, $T_{a}$, can be estimated based on the time the smoke layer in a room takes to drop to the critical height [14]: 


$$
T_{a}=A_{r} \cdot\left(H_{r}-H_{c r i t}\right) /(M-E)
$$

where, $A_{r}$ is the area of the room, $\mathrm{m}^{2} ; H_{r}$ is the height of the room, $\mathrm{m} ; H_{\text {crit }}$ is the critical height of the smoke, i.e. the height from the ground of the smoke when it descends to the level of the eyes, $\mathrm{m} ; M$ is the amount of smoke generated, $\mathrm{m}^{3} / \mathrm{s} ; E$ is the amount of effectively discharged smoke, $\mathrm{m}^{3} / \mathrm{s}$.

The amount of smoke generated by solid combustibles per unit time [15] can be computed by:

$$
M=\eta B\left[v_{y}^{0}+1.0161\left(\alpha_{m}-1\right) v_{0}\right]\left(\mathrm{Nm}^{3} / \mathrm{kg}\right)
$$

where, $\eta$ is the incomplete combustion coefficient: $\eta=B_{j} / B\left(B_{j}\right.$ is the actual consumption of combustibles, $\mathrm{kg} / \mathrm{h}) ; B$ is the total consumption of combustibles, $\mathrm{kg} / \mathrm{h}$.

The theoretical amount of smoke generated by solid combustibles can be obtained by:

$$
v_{y}^{0}=0.248^{*} Q_{d w}^{y} / 1000+0.77\left(\mathrm{Nm}^{3} / \mathrm{kg}\right)
$$

where, $\alpha_{m}$ is the excess air coefficient: $\alpha_{m}=V / V_{0}(V$ is the actual consumption of the air, $\mathrm{m}^{2} ; V_{0}$ is the theoretical consumption of the air, $\mathrm{m}^{2}$ ).

The theoretical consumption of the air can be obtained by:

$$
V_{0}=0.25 Q_{d w}^{y} / 1000+0.28\left(\mathrm{Nm}^{3} / \mathrm{kg}\right)
$$

Since the underground spaces are enclosed, most underground buildings discharge smoke mechanically. Thus, the amount of effectively discharged smoke $E$ can be determined per unit area per unit time:

$$
E=v F_{i}\left(\mathrm{~m}^{3} / \mathrm{h}\right)
$$

where, $v$ is the amount of smoke discharged per unit area per unit time, $\mathrm{m}^{3} /\left(\mathrm{m}^{2} \cdot \mathrm{h}\right) ; F_{i}$ is the floor area of fire compartment $i$, $\mathrm{m}^{2}$.

\subsubsection{Determination of the RSET}

The RSET is related to personnel behavior, crowd features, and the sensitivity of the alarm system. The RSET value is the sum of fire detection time $t_{b}$, reaction time $t_{f}$ and evacuation time. In the safe evacuation mode, the evacuation time is further divided into the horizontal evacuation time $t_{l}$, vertical evacuation time $t_{2}$ and exit evacuation time $t_{3}$.

$$
T_{R S E T}=t_{b}+t_{f}+t_{1}+t_{2}+t_{3}
$$

The horizontal evacuation time stands for the sum of the time from a person in the underground space to a vertical escape route and the time spent by the personnel on the horizontal escape route:

$$
t_{1}=\sum \frac{l}{v}
$$

where, $l$ is the distance between any point in the underground space to a vertical escape route, $\mathrm{m} ; v$ is the walking speed, $\mathrm{m} / \mathrm{s}$.

The vertical evacuation time refers to the time a person spends in the vertical escape route and the vertical evacuation system:

$$
t_{2}=h_{p} / v_{d}+\min \left(t_{e}, t_{s}\right)
$$

where, $t_{e}$ is the time to escape by elevator in the vertical evacuation system, $\mathrm{s} ; t_{s}$ is the time to escape by stairs in the vertical evacuation system, $\mathrm{s} ; h_{p}$ is the height of the vertical escape route, $\mathrm{m} ; v_{d}$ is the downward speed of the person, $\mathrm{m} / \mathrm{s}$.

The time to escape by elevator in the vertical evacuation system can be computed by:

$$
t_{e}=2 h P_{1} /\left(n_{e} Q v_{e}\right)
$$

where, $h$ is the distance between shelter and exit, $\mathrm{m} ; P_{l}$ is the number of personnel evacuating by elevators, persons; $n_{e}$ is the number of elevators, each; $Q$ is the rated load of each elevator, persons; $v_{e}$ is the elevator speed, $\mathrm{m} / \mathrm{s}$.

The time to escape by stairs in the vertical evacuation system can be computed by:

$$
t_{s}=\sqrt[1.37]{8.04 P_{2} / W}
$$

where, $P_{2}$ is the number of personnel evacuating via stairs, persons; $W$ is the effective width of the stairs, $m$.

The exit evacuation time means the time for a person to move from the vertical evacuation system to the ground:

$$
t_{3}=\frac{\sum p A_{r}}{\sum N_{e f f} B_{\text {aval }}}
$$

where, $\rho$ is the crowd density, persons $/ \mathrm{m}^{2} ; A_{r}$ is the area of the room, $\mathrm{m}^{2} ; N_{\text {eff }}$ is the effective traffic capacity, persons $/ \mathrm{m} \cdot \mathrm{s}$; $B_{\text {avail }}$ is the available width of the gate, $\mathrm{m}$. The effective traffic capacity of an exit refers to the number of personnel can pass through the exit per unit gate width per unit time. Its relationship with the crowd density can be empirically obtained by $N_{\text {eff }}=1.34 \rho\left(1-e^{-1.93(1 / \rho-1 / 5.4)}\right)$.

\section{CASE STUDY}

\subsection{Project overview}

Located under Wuhong Road, Hontudi Station of CRT Line 10 , with north-south orientation, lies beneath the station of the same name of CRT Line 6. Together, the two stations form a cross-shape interchange station. The station hall of Line 10 is $222 \mathrm{~m}$ from north to south, covering an area of $11,188.8 \mathrm{~m}^{2}$. The hall is buried at the depth of $94.467 \mathrm{~m}$, about the height of a 31-story building, and 4.7 times the depth of standard bomb shelter $(20 \mathrm{~m})$. In fact, the station boasts the deepest underground public space in all metro stations across China.

There are four entrances/exits at this station. Among them, entrances/exits 5, 6 and 7 are connected to Hongtudi Station of CRT Line 6, and entrance/exit 8 is reserved. The journey from the station hall to the ground is extremely long. A passenger needs to climb up 4 escalators from the hall to the entrances/exits of the station of Line 6, and then ride 2 more escalators to the ground. The entire interchange station has 91 escalators, more than any other metro station in China. 


\subsection{Problem analysis}

The current fire protection design of Hongtudi Station of CRT Line 10 has three main problems.

First, the underground public space of the station is buried at $94 \mathrm{~m}$, far deeper than the buried depth $(10 \mathrm{~m})$ of underground public spaces for both peacetime and wartime purposes in The Code for Fire Protection Design of Civil Air Defense Works (GB 50098-2009).

Second, each fire compartment of the hall is only provided with a ceiling screen and a few fire hydrants (Figure 8 ). The area of each fire compartment reaches $6,372.2 \mathrm{~m}^{2}$ (Figure 9), exceeding the limit $\left(2,000 \mathrm{~m}^{2}\right)$ specified in GB 50098-2009.

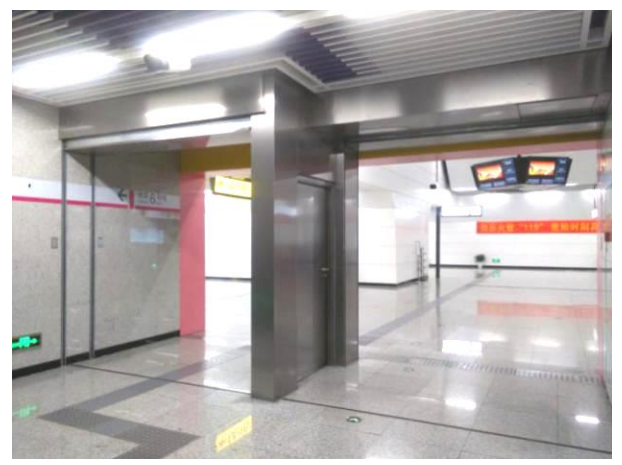

Figure 8. The entrances/exits of the transfer channels

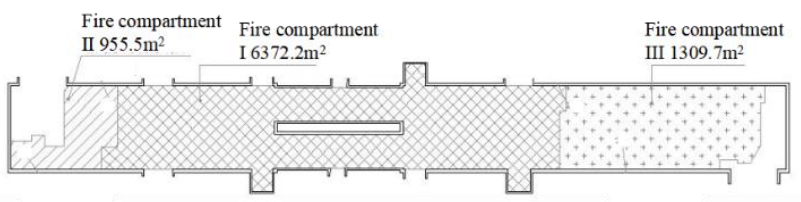

Figure 9. Fire compartments of the hall

Third, the underground civil air defense work of the station only has four exits leading to the outdoor (Figure 10), i.e. entrance/exit 1, 3A, 3B and 8 . Neither the number nor the distance satisfy the relevant provisions that a fire compartment needs two straight outdoor evacuation exits in GB50016-2014 and GB 50098-2009.

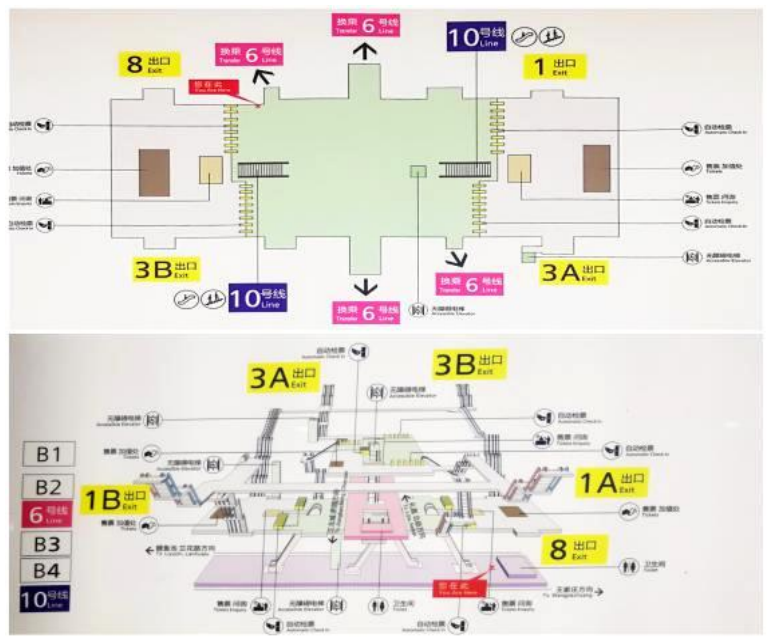

Figure 10. Sketch map of Hongtudi Station of CRT Line 10

The above problems are typical ones in the development and utilization of ultradeep underground public spaces.
Because the relevant codes are relatively outdated, these problems should be solved innovatively [16]. In this paper, the building information modelling (BIM) is adopted to simulate the application of our safe evacuation mode to Hongtudi Station of CRT Line 10.

\subsection{BIM-based simulation}

The BIM can simulate the real information of a building based on the relevant digital information of the construction project [17]. The core idea is to set up a virtual 3D model by digital technology, and provide the model with a complete and realistic library of engineering information. The 3D model of the actual building facilitates the simulation of personnel evacuation. The library contains not only the geometry, professional attributes and states of building components, but also the states of non-component objects like spaces and motions [18]. Therefore, the BIM offers a realistic platform for simulating the effects of safe evacuation modes.

\subsubsection{Creating simulation scenes}

First, a 1:200 model of Hongtudi Station of CRT Line 10 was created by the BIM (Figure 11). The model provides an intuitive representation of the public facilities and entrances/exits in the hall and the platform. The information of the entire station is displayed clearly, improving the judgements by evacuees.

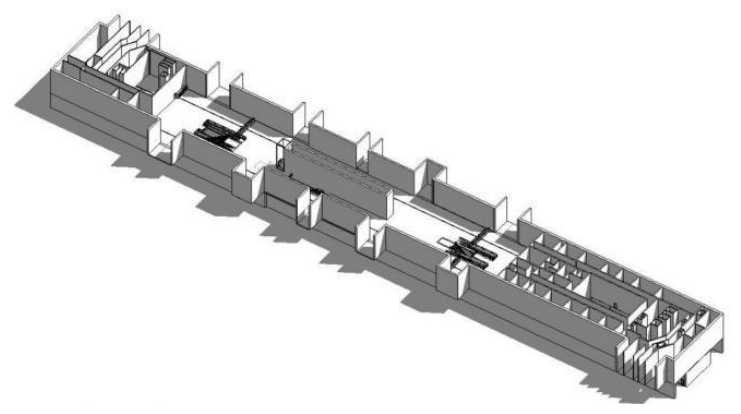

Figure 11. The model of Hongtudi Station of CRT Line 10

Based on the original model, a safe evacuation mode was established (Figure 12). The components of the mode were arranged according to the areas, distances and facility positions (Figure 13).

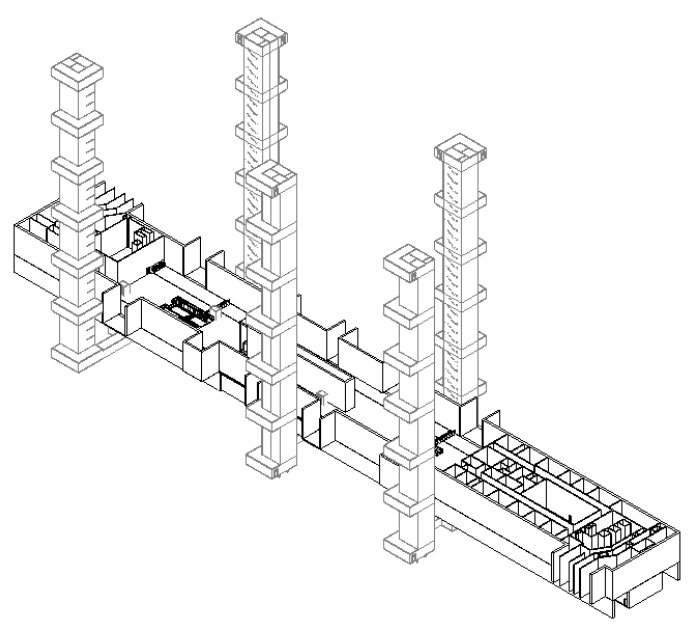

Figure 12. The safe evacuation mode for Hongtudi Station of CRT Line 10 


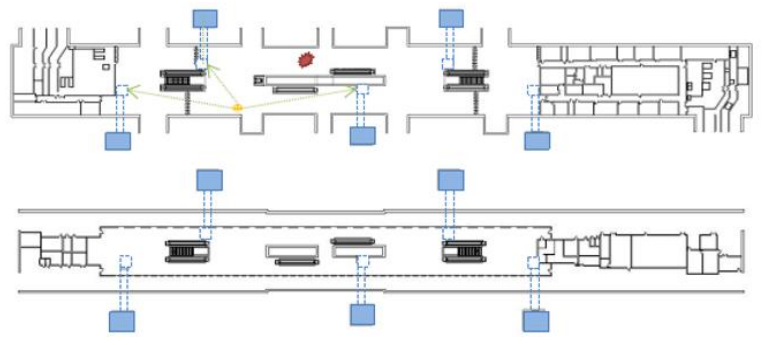

Figure 13. The safe evacuation plan for Hongtudi Station of CRT Line 10

As shown in the above figures, if the fire occurs in the hall, the platform will serve as a shelter for evacuees. In this case, the safe evacuation mode consists of platform, hall, horizontal escape route, vertical evacuation system and exit. If the fire occurs in the platform, the safe evacuation mode consists of horizontal evacuation, vertical escape route, shelter, horizontal escape route, vertical evacuation system and exit.

\subsubsection{Simulation features}

The BIM-based simulation has many advantages. First, the building-specific fire scene simulation is more than the simple modelling of the building structure. It can verify the effects of emergency evacuation mode. Besides, the 3D modelling and evacuation simulation are both visualized. The evacuees can clearly see their positions and choose the correct escape route quickly. Finally, the evacuation mode is continuously optimized to minimize the egress time, and, if possible, simplify the evacuation route and access more information on the building. In this way, the personnel can be evacuated quickly before the ASRT.

\subsubsection{Results analysis}

In the current Code for Design of Metro (GB50157-2013), it is specified that the stairways and evacuation channels at the exit should be wide enough to ensure that all the passengers in a train and the passengers waiting on the platform can evacuate from the platform within $6 \mathrm{~min}$, if a fire breaks out under the long-term peak hour passenger flow. Therefore, the ASRT of our simulation was set to $6 \mathrm{~min}$. The sum of fire detection time and reaction time was empirically set to less than 30 s.

Since only a few staff could enter the working area, the simulation only considers the area $\left(4,357.75 \mathrm{~m}^{2}\right)$ in which passengers can move freely (Figure 14). A total of 5 vertical evacuation systems were deployed for this area, and the personnel were distributed evenly in the 5 systems. The crowd density was computed as $700 / 4,357.75=0.16$ persons $/ \mathrm{m}^{2}$, according to the maximum passenger capacity (700) of the station.

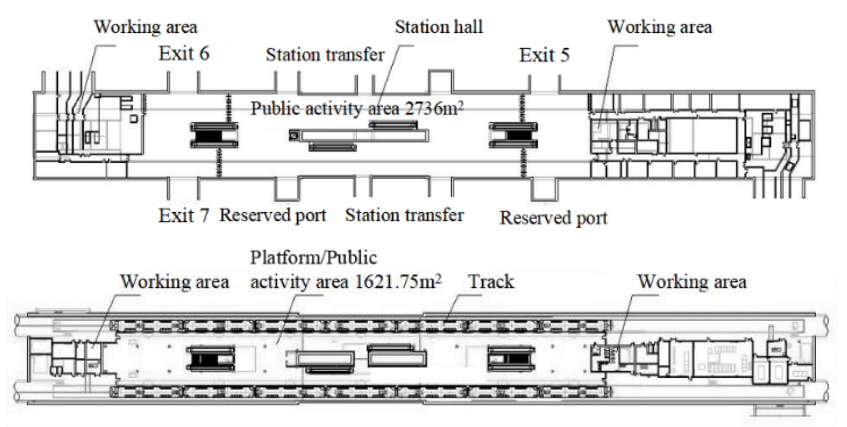

Figure 14. The open area of hall/platform
Referring to the Fire Protection Handbook of National Fire Protection Association, the author analyzed the evacuation speeds under fire on Pathfinder and FDS [19], and then established the relationship between crowd walking speed and fire scenes (Table 2). Based on the data in the table, the horizontal movement speed was set to $2.0 \mathrm{~m} / \mathrm{s}$ and the downward speed along the stairway in vertical escape routes was set to $1.36 \mathrm{~m} / \mathrm{s}$ [20].

Table 2. The relationship between crowd walking speed and fire scenes. Source:Research on evacuation of personnel under fire field based on Pathfinder and FDS

\begin{tabular}{cc}
\hline Fire scenes & Walking speed $(\mathbf{m} / \mathbf{s})$ \\
\hline Normal walk & 1.0 \\
Fast walk & 2.0 \\
Walk in a place with 1.5 persons $/ \mathrm{m}^{2}$ & 1.0 \\
\hline
\end{tabular}

In the station, the evacuees select the nearest escape channel. It is measured that the farthest channel is $35.5 \mathrm{~m}$ away, and the horizontal escape route is $9.5 \mathrm{~m}$ long. Thus, the total horizontal movement distance in the safe escape mode $l_{\text {max }}$ equals $45 \mathrm{~m}$. Then, the horizontal evacuation time can be obtained as:

$$
t_{1}=\sum \frac{l}{v}=l_{\max } / v=45 / 2=22.5 \mathrm{~s}
$$

In each vertical evacuation system, there is a stairway with the net width of $1.5 \mathrm{~m}$, and two fire elevators with the rated load of 20 persons. The normal speed of the elevators is above $2.5 \mathrm{~m} / \mathrm{s}$. Here, the speed is set to $2.8 \mathrm{~m} / \mathrm{s}$. The height of each vertical escape route was set to $5 \mathrm{~m}$. Then, the vertical evacuation time can be obtained as:

$$
\begin{gathered}
t_{2}=h_{p} / v_{d}+\min \left(t_{e}, t_{s}\right) \\
=h_{p} / v_{d}+\min \left(\frac{2 h P_{1}}{n_{e} Q v_{e}}, \sqrt[1.37]{8.04 P_{2} / W}\right) \\
=5 / 1.36+\min \left(\frac{2 \times 95 \times 700}{5 \times 2 \times 20 \times 2.8}, \sqrt[1.37]{8.04 \times 700 / 1.5}\right) \\
=241.18 \mathrm{~s}
\end{gathered}
$$

The crowd density $\rho$ was empirically derived from the rated load of elevators and the area of the shelter of the vertical evacuation system as 0.46 persons $/ \mathrm{m}^{2}$. Whereas the available width of each gate is $1.5 \mathrm{~m}$, the exit evacuation time can be computed as:

$$
\begin{aligned}
& t_{3}=\frac{\sum p A_{r}}{\sum N_{\text {eff }} \boldsymbol{B}_{\text {avail }}} \\
& =\frac{0.46 \times 9.6 \times 9}{1.34 \times 0.46 \times\left(1-\mathrm{e}^{-1.93(1 / 0.46-1 / 5.4)}\right) \times 1.5}=43.93 \mathrm{~s}
\end{aligned}
$$

Thus, the RSET value can be obtained as:

$$
\begin{aligned}
T_{R S E T}=t_{b}+t_{f}+t_{l}+t_{2}+t_{3}= & 30+22.5+241.18+43.93=337.61 \mathrm{~s} \\
& <T_{\mathrm{ASRT}}=360 \mathrm{~s}
\end{aligned}
$$

The result shows that the personnel in the station can be evacuated safety with 5 vertical evacuation systems and our safe evacuation mode. In actual application, the number and proportion of elevators and stairways in each vertical 
evacuation system can be adjusted according to the buried depth and the number of evacuees. Through the adjustment, the safe evacuation mode will become more flexible, effective and reliable, and adapt to different ultradeep underground public spaces.

\subsubsection{Further improvement}

Both the building environment and crowd condition were considered in the above simulation of safe evacuation in fire. However, the simulation ignores the effects of health and mental conditions. It is assumed that all evacuees are healthy adults, failing to consider vulnerable groups. What is more, the actual evacuation is more changeable than the simulated process. For example, the evacuees tend to follow the crowd and wander back and forth in the station. In other words, our simulation mainly deals with the ideal situation.

\section{CONCLUSIONS}

In this paper, a new safe evacuation mode is developed, involving horizontal evacuation, vertical downward evacuation, temporary shelter, horizontal evacuation, vertical evacuation and exit evacuation. Our mode reduces the safety threats to evacuees, providing a safe and feasible evacuation method for large crowds. In addition, a vertical evacuation system was designed for the safe evacuation mode. The calculation results show that the transport capacity of the vertical evacuation system can ensure timely evacuation. Of course, our simulation is slightly idealized, and the obtained RSET may be a little shorter than the RSET in actual evacuation. Overall, our research results shed important new light on the safe evacuation in ultradeep underground public spaces.

\section{ACKNOWLEDGMENT}

This work is supported by Chongqing Fundamental and Frontier Research (cstc2017jcyjAX0260); Chongqing Social Career and People's Livelihood Guarantee Science and Technology Innovation Special Program (cstc2016shmszx30017); Chongqing Graduate Education Innovation Fund (CYS18227).

\section{REFERENCES}

[1] Castle, C.J.E., Longley, P.A. (2006). A GIS-based spatial decision support system for emergency services: London's King's cross St. pancras underground station. Centre for Advanced Spatial Analysis, (10): 867-881. https://doi.org/10.1007/3-540-27468-5 62

[2] Alexander, M.E., Cruz, M.G. (2013). Are the applications of wildland fire behaviour models getting ahead of their evaluation again? Environmental Modelling \& Software, 41: 65-71. https://doi.org/10.1016/j.envsoft.2012.11.001

[3] Yoneyama, N., Toda, K., Aihata, S., Yamamoto, D. (2009). Numerical analysis for evacuation possibility from small underground space in urban flood. Advances in Water Resources and Hydraulic Engineering, 107-117. https://doi.org/10.1007/978-3-540-89465-0_21
[4] Li, J.Y. (2014). On the underground space partition and evacuation design analysis. Journal of Chinese Poeple's Admed Police Force Academy, 30(2): 41-42. http://dx.chinadoi.cn/10.3969/j.issn.10082077.2014.02.012

[5] Zhi, G.S., Lo, S.M., Fang, Z. (2003). A graph-based algorithm for extracting units and loops from architectural floor plans for a building evacuation model. Computer-Aided Design, 35(1): 1-14. https://doi.org/10.1016/S0010-4485(01)00171-3

[6] Han, X. (2006). The characteristics of major disasters in urban underground space and its prevention. Journal of Shanghai Institute of Urban Management, 3: 17-20. http://dx.chinadoi.cn//10.3969/j.issn.16747739.2006.03.025

[7] Du, B.L. (2007). Statistic analysis of foreign underground fire accidents cases. Fire Science and Technology, 26(2): 214-217. http://dx.chinadoi.cn/10.3969/j.issn.10090029.2007.02.029

[8] Hu, W.S., Li, J.Z., Li, Z.L., Cui, Y. (2015). Vertical evacuation body in deep underground public space: Taking Qingdao underground civil defense engineering as an example. South Architecture, 5: 89-92. http://dx.chinadoi.cn/10.3969/j.issn.10000232.2015.05.089

[9] Broere, W. (2016). Urban underground space: Solving the problems of today's cities. Tunnelling and Underground Space Technology, 55: 245-248. https://doi.org/10.1016/j.tust.2015.11.012

[10] Yan, P., Wang, H., Wang, Y.H. (2008). Probing into the design of underground refuge space. Chinese Journal of Underground Space and Engineering, 4(1): 12-15. http://dx.chinadoi.cn/10.3969/j.issn.16730836.2008.01.003

[11] Guo, X.M., Yao, B., Li, Z., Zuo, T.C. (2018). Optimization study on high-rise building collaborative evacuation by combined use of stairs with elevators. Fire Safety Science, 1: 53-61. http://dx.chinadoi.cn/10.3969/j.issn.10045309.2018.01.07

[12] Tian, Y.M. (2006). Research on safety evacuation evaluation method for highrise buildings. Fire Science and Technology, 25(1): 33-36. http://dx.chinadoi.cn/10.3969/j.issn.10090029.2006.01.007

[13] Admiral, J.B.M. (2006). A bottom-up approach to the planning of underground space. Tunneling and Underground Space Technology, 21(3-4): 464-465. https://doi.org/10.1016/j.tust.2005.12.102

[14] Fang, Y.G., Zhu, H.H., Yan, Z.G. (2010). Research of evacuation and rescue measures in Shanghai Yangtze River tunnel. Chinese Journal of Underground Space and Engineering, 6(2): 418-422. http://dx.chinadoi.cn/10.3969/j.issn.16730836.2010.02.037

[15] Liang, Q., Wei, D. (2011). A numerical simulation model of a pressurized smoke-removable air supply system in a subway station. Journal of Safety and Environment, 11(4):

226-230. http://dx.chinadoi.cn/10.3969/j.issn.10096094.2011.05.052

[16] Nguyen, K.T.Q., Mendis, P., Fernando, S. (2019). Novel modelling approach for evacuation strategies of tall 
towers-A case study of Lotus Tower. Building Engineering, $\quad 25$ : 166-172. https://dx.doi.org/10.1016/j.jobe.2019.100763

[17] Chan, D.W., Olawumi, T.O., Ho, A.M. (2019). Perceived benefits of and barriers to Building Information Modelling (BIM) implementation in construction: The case of Hong Kong. Journal of Building Engineering, 25: 100764. https://doi.org/10. 1016/j.jobe.2019.100764

[18] Su, X.C., Cai, H., Guo, D.J. (2014). Application of BIM technology in development of city underground space. Journal of PLA University of Science and Technology (Natural Science Edition), 15(3): 219-224. http://dx.chinadoi.cn/10.7666/j.issn.10093443.20140402003

[19] Schadschneider, A., Klingsch, W., Klüpfel, H., Kretz, T., Rogsch, C., Seyfried, A. (2009). Evacuation dynamics: Empirical results, modeling and applications. Encyclopedia of Complexity and Systems Science, 31423176. https://doi.org/10.1007/978-0-387-30440-3_187

[20] Hong, X. (2015). An evacuation efficiency contribution index of public building's space models. In 2015 3d International Conference on Advanced Information and Communication Technology for Education (ICAICTE2015), Atlantis Press. https://doi.org/10.2991/icaicte15.2015 .90 